\title{
Viscosupplementation as a treatment of internal derangements of the temporomandibular joint: retrospective study*
}

\author{
Viscossuplementação como tratamento das alterações internas da articulação \\ temporomandibular: estudo retrospectivo
}

Daniel Bonotto ${ }^{1}$, Eduardo Machado ${ }^{1}$, Rafael Schlogel Cunali ${ }^{1}$, Paulo Afonso Cunali ${ }^{1}$

${ }^{*}$ Received from Federal University of Paraná, Curitiba, PR, Brazil.

\section{ABSTRACT}

BACKGROUND AND OBJECTIVES: There are many non invasive treatment modalities for internal temporomandibular joint derangements described in the literature, including counseling, drug therapy, physical therapy and interocclusal devices. However, some patients become refractory to conservative treatments and procedures such as arthrocentesis, arthroscopy and temporomandibular joint surgery are indicated. Viscosupplementation is a less invasive, low cost approach with good short and long term results. This study aimed at discussing viscosupplementation to treat internal temporomandibular joint alterations with results after four months of follow-up.

METHODS: Participated in the study 55 patients with reducing and non reducing disc displacement and osteoarthritis refractory to conservative treatments who were submitted to sodium hyaluronate infiltrations. There has been statistically significant pain improvement for all groups.

RESULTS: Patients with non reducing disc displacement and osteoarthritis had significant mouth opening improvement. Such results were constant along the four months of follow-up. CONCLUSION: Viscosupplementation with sodium hyaluronate may be considered a good alternative to functionally reestablish temporomandibular joint in the short term in patients with internal alterations refractory to conservative treatments.

Keywords: Hyaluronic acid, Temporomandibular joint, Treatment.

1. Federal University of Paraná, Curitiba, PR, Brazil.

Submitted in May 16, 2014.

Accepted for publication in January 27, 2014

Conflict of interests: none.

Correspondence to:

Paulo Afonso Cunali

Rua Cel. Napoleão Marcondes França, 360

80040-270 Curitiba, PR, Brasil.

E-mail: pacunali10@gmail.com

(C) Sociedade Brasileira para o Estudo da Dor

\section{RESUMO}

JUSTIFICATIVA E OBJETIVOS: As formas de tratamento consideradas não invasivas para as alteraçóes internas das articulações temporomandibulares descritas na literatura são muitas, incluindo aconselhamento, farmacoterapia, fisioterapia e dispositivos interoclusais. No entanto, alguns pacientes tornamse refratários aos tratamentos conservadores, sendo indicados procedimentos como artrocentese, artroscopia e cirurgias das articulações temporomandibulares. A viscossuplementação é uma abordagem pouco invasiva, de baixo custo e com bons resultados em curto e médio prazo. O objetivo deste estudo foi discutir a viscossuplementação no tratamento das alteraçóes internas da articulação temporomandibular com os resultados depois de quatro meses de acompanhamento.

MÉTODOS: Cinquenta e cinco pacientes com deslocamento de disco com redução, deslocamento de disco sem redução e osteoartrite refratários a tratamentos conservadores foram submetidos a infiltração com hialuronato de sódio. Foi observada melhora estatisticamente significativa para dor nos três grupos.

RESULTADOS: Pacientes com deslocamento de disco sem redução e osteoartrite apresentaram aumento significativo da abertura bucal. Estes resultados se mantiveram constantes ao longo dos quatro meses de acompanhamento.

CONCLUSÁO: A viscossuplementação com hialuronato de sódio pode ser considerada uma boa alternativa no reestabelecimento funcional da articulação temporomandibular em curto prazo em pacientes com alteraçóes internas refratárias a tratamentos conservadores.

Descritores: Ácido hialurônico, Articulação temporomandibular, Tratamento.

\section{INTRODUCTION}

Among temporomandibular disorders (TMD), the derangement of the condyle-disc complex derives from the collapse of the normal rotational function of the disc on the condyle. Usually this situation occurs with elongation of the discal collateral ligaments and the inferior retrodiscal lamina. This group of articular TMD includes reducing and non-reducing disk displacement. These disorders are, many times, associated with inflammatory alterations such as synovitis, capsulitis 
and retrodiscitis or degenerative alterations like osteoarthrosis and osteoarthritis ${ }^{1}$.

Generally the primary protocol to control TMD prioritizes the simplest measures, which are reversible and less invasive ${ }^{1}$. However since intracapsular dysfunctions are often a result of pathologies of the articular surface, that is, of existing structural alterations, the conservative treatment sometimes proves to be ineffective. Several forms of treatment for internal dysfunctions of the temporomandibular joint (TMJ) are supported by the literature: functional rest, non-steroid antiinflammatory drugs, oral splint, physical therapy support exercises, intra-articular corticosteroid injection, arthrocentesis, arthroscopy, open joint surgery for TMJ, among others.

Viscosupplementation with intra-articular injection of sodium hyaluronate $(\mathrm{SH})$ - the sodium salt of the hyaluronic acid (HA) - was first used as a treatment for traumatic arthritis on racehorses ${ }^{2}$, subsequently used in humans to treat osteoarthritis in large joints such as knees, hips and shoulder. At In 1979 , sodium hyaluronate started to be indicated for internal TMJ alterations ${ }^{3}$, and since then some studies have tried to assess the effectiveness of the technique, as well as to establish a protocol to its utilization.

A multicenter randomized double blind and placebo-controlled study with 121 patients has presented promising results $^{4}$. A group of 80 patients received $\mathrm{SH}$ injections $(35 \mathrm{had}$ reducing disk displacement (RDD), 8 presented non-reducing disk displacement (NRDD), and 37 with degenerative alterations of TMJ), while 41 patients received injection with saline solution (15 with RDD, 6 with NRDD and 20 with degenerative alterations of TMJ). Results showed that for patients with RDD, joint sounds were subjectively reduced in both groups, without statistically significant difference, but the degree and importance of the mandibular deviation improved significantly in the SH group. Patients with NRDD treated with $\mathrm{SH}$ presented an improvement of mouth opening in the first five weeks when compared to the group treated with placebo, however, statistically there was no significant difference. Regarding pain assessment with visual analogue scale (VAS), results indicated that the group treated with $\mathrm{SH}$ obtained significant improvement in comparison to placebo group.

Other study 5 performed a retrospective study comparing the effectiveness of intra-articular injection of $\mathrm{SH}$ to the absence of treatment in patients with disk NRDD. A group of 60 patients with NRDD was submitted weekly to an injection of $1 \mathrm{ml}$ of SH during 5 weeks. A second group of 76 patients diagnosed with NRDD was only monitored without receiving any treatment (control group). During a period of two years, patients were examined monthly regarding mandibular movement range and joint pain. After this period, $82.3 \%$ of patients from the $\mathrm{SH}$ group presented an improvement (defined by the authors as mouth opening range over $35 \mathrm{~mm}$ and absence of joint pain) against $64.7 \%$ from the control group, indicating statistically significant difference. Furthermore, it was observed that patients from the $\mathrm{SH}$ group presented fast remission of the symptomatology when compared to untreat- ed patients, concluding that SH appears to be an effective method for the treatment of NRDD.

Other authors have assessed the efficacy of intra-articular injection of $\mathrm{SH}$ in 38 patients presenting RDD by a randomized placebo-controlled clinical trial ${ }^{6}$. Patients from $\mathrm{SH}$ group received two $\mathrm{SH}$ injections in the upper compartment of the affected TMJ while control group patients received saline solution injection. SH group presented statistically significant improvement for all evaluated aspects, while the placebo group presented significant improvement only for pain. It was concluded that $\mathrm{SH}$ injection is an efficient therapeutic option for the treatment of RDD in a six month period ${ }^{6}$.

Comparison of injections of corticosteroid (CO) and sodium hyaluronate $(\mathrm{SH})$ in 33 patients with arthralgia and RDD unresponsive to conservative treatments was also performed. In that controlled double-blind study, 18 patients received two infiltrations with $0.5 \mathrm{~mL} \mathrm{SH} 1 \%$ with a two weeks interval, while 15 patients received corticosteroid injection $(0.5 \mathrm{~mL}$ of bethametasone). Evolution was assessed using a questionnaire regarding pain, functional limitation, articular sounds and symptoms persistence, and a clinical evaluation. VAS indicated significant improvement, with a reduction of the initial algic condition of $30 \%$ for $\mathrm{SH}$ group and of $40 \%$ for the $\mathrm{CO}$ group ${ }^{7}$.

A randomized controlled clinical trial with 67 patients with RDD, NRDD or degenerative alteration of TMJ compared injections of sodium hyaluronate and corticosteroid. The work group received $0.5 \mathrm{~mL}$ of $\mathrm{SH}$ associated to $1 \mathrm{ml}$ bupivacaine $1 \%$ once a week totalizing from three to four injections. Control group received $0.5 \mathrm{~mL}$ of prednisolone $2.5 \%$ with $1 \mathrm{ml}$ of bupivacaine $1 \%$ once a week, total of three or four injections. During 5 weeks monitoring period both groups presented significant improvement of pain and function, with no statistically significant difference between them ${ }^{8}$.

A randomized double-blind clinical trial evaluated 41 patients with rheumatoid arthritis in the temporomandibular joints, dividing them in three groups: 14 individuals were treated with intra-articular SH injections; 14 with corticosteroid injections; 13 with saline solution injection. Monitoring period was of four weeks, and an improvement of symptoms and in the clinical indexes of dysfunction was observed in all groups. Better results were observed in the groups treated with $\mathrm{SH}$ and $\mathrm{CO}^{9}$.

One study reports that 6 patients $(7.5 \%$ of the sample) presented reactions such as discomfort and edema at the injection site $e^{4}$. Other author claims that 13 patients $(37.1 \%$ of the sample) who received $\mathrm{SH}$ injection complained of pain during the procedure and within three days, 3 patients $(8.5 \%$ of the sample) presented acute malocclusion at the injection side and muscular strength reduction ${ }^{8}$.

This study aimed to at discussing and evaluating the viscosupplementation technique with $\mathrm{SH}$ injection as an alternative for the treatment of TMJ internal alterations by means of 55 case reports. 


\section{METHODS}

This is a retrospective study performed by assessment of medical records of patients treated at the TMD and Orofacial Pain Clinic of the Federal University of Paraná (UFPR) and at private clinic. Fifty five patients with articular TMD diagnosis RDD, NRDD and osteoarthritis (OA) - and unresponsive to conservative treatments, such as occlusal splints and mandible exercises, received viscosupplementation on the affected TMJ. Diagnostic clinical criteria on RDC/TMD were followed by two specialists in TMD and orofacial pain throughout the assessment of all patients. The technique described by Bonotto, Custodio and Cunali ${ }^{10}$ for sodium hyaluronate $1 \mathrm{~mL}$ infiltration was utilized in every procedure. Two specialists in TMD and orofacial pain performed all procedures during the period from February 2006 to March 2011. Both examiners were calibrated to data collection, and executed the technique. All patients have received from one to three infiltrations of $\mathrm{SH}$ with at least 10 days between them. Throughout the postoperative period patients were instructed to continue with routine conservative treatment, oral splint and/or mandibular exercises. Non-steroid anti-inflammatory drug was prescribed for the three days subsequently to the procedure.

Patients' evolution regarding temporomandibular pain complains, was assessed using a VAS before and 4 months after the procedure. To evaluate alteration concerning mandibular function, measurements of interincisal opening were also performed with the same interval. The same professionals that had executed previous procedures performed all assessments. In order to compare average mouth opening and average indexes of the VAS, before and after treatment, the Wilcoxon signed rank test was applied. A 95\% confidence interval was considered.

This study was approved by the Ethics Committee, Federal University of Paraná under number 1245.170.11.2010.

\section{RESULTS}

From the 55 evaluated patients, 46 were females $(83.64 \%)$ and 9 were males (16.36\%). Average age was $32.98 \pm 15.84$ years. After clinical assessment using RDC/TMD criteria, diagnosis was RDD for $21.8 \%$ (12 patients), NRDD for $54.5 \%$ (30 patients) and OA for $23.6 \%$ (13 patients). Table 1 shows mouth opening and VAS data at baseline.

Figure 1 indicates patient's evolution for mandibular function before and after the viscosupplementation treatment. Statistic

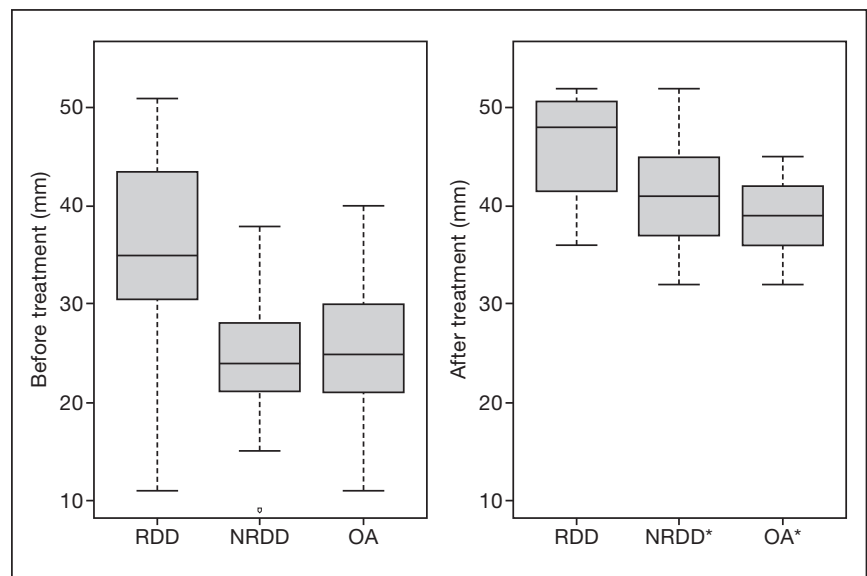

Figure 1. Interincisal opening average pre and post treatment for the three groups

RDD: reducing disc displacement; NRDD: non-reducing disc displacement; OA osteoarthritis.

*Statistical difference was observed in patients with NRDD and OA using Wilcoxon signed rank test $(p<0.001)$.

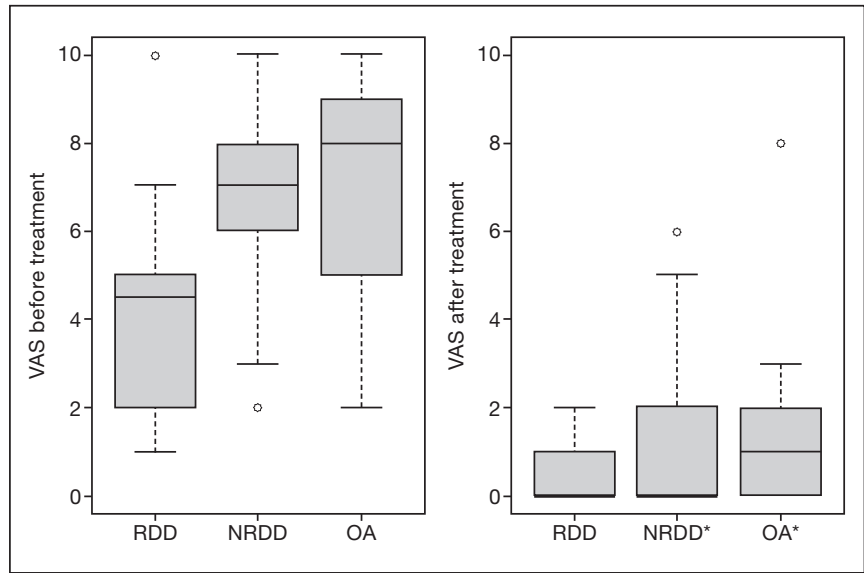

Figure 2. TMJ pain intensity measured by visual analog scale (0-10 scale) before and after treatment for all groups

RDD: reducing disc displacement; NRDD: non-reducing disc displacement; $\mathrm{OA}$ : osteoarthritis

*Statistically significant difference was observed for all groups at Wilcoxon signed rank test $(p<0.001)$.

significant improvement of the mandibular function was observed in patients with RDD and OA $(\mathrm{p}<0.001)$.

Figure 2 shows the improvement for temporomandibular disorders pain complaint, which was statistically significant for all groups: RDD, NRDD and OA.

Table 1: Mouth opening (in millimeters) and visual analogue scale (0-10 scale) at baseline for the three groups

\begin{tabular}{|c|c|c|c|c|c|c|}
\hline & \multicolumn{3}{|c|}{ Mouth opening at baseline } & \multicolumn{3}{|c|}{ VAS at baseline } \\
\hline & Medium & Minimum & Maximum & Medium & Minimum & Maximum \\
\hline RDD & 35.5 & 11.0 & 51.0 & 4.2 & 1 & 10 \\
\hline NRDD & 24.3 & 9.0 & 38.0 & 6.5 & 2 & 10 \\
\hline OA & 26.0 & 11.0 & 40.0 & 7.1 & 2 & 10 \\
\hline Total & 27.1 & & & 6.1 & & \\
\hline
\end{tabular}

RDD: reducing disc displacement; NRDD: non-reducing disc displacement; OA: osteoarthritis 
Complaints of mild discomfort in the first 48 hours were reported by $9 \%$ of patients, while $7.2 \%$ of them have experienced an open bite in the injection side.

\section{DISCUSSION}

There is no precise indication for viscosupplementation in the literature, however there seems to be a consensus on its utilization in cases of internal symptomatic alteration of TMJ, specially in the presence of limited range of movement. During the monitoring of the reported cases, viscosupplementation demonstrated to be an efficient treatment to control pain in patients with RDD, NRDD and OA. This result is consonant with those presented by several authors $s^{4,6-9}$. Furthermore, viscosupplementation improved mandibular function of patients with limited mouth opening caused by RDD and OA, corroborating others, ${ }^{5,9}$.

Results regarding improvement of mandibular function observed in this study may be considered expressive, since they refer to patients who did not respond to conservative treatment. However it must be highlighted that this is a retrospective study based on chart review with short term follow-up and that the same examiners have performed both treatment and postoperative assessment procedures. Therefore some obliquity may be considered in the interpretation of results. Maintenance of conservative treatment during the follow-up period may have contributed to improvement of patients. However, these patients were refractory to conservative therapy alone. Furthermore, in clinical practice viscosuplementation should be associated with conservative treatment.

HA is a mucopolysaccharide acid and an essential component of animal tissues. HA is composed by multiple alternating units of D-glucuronic acid and $\mathrm{N}$-acetylglucosamine, forming highly viscous gelatinous solution due to its elevated hydrophilicity ${ }^{11}$. It is the major component of the synovial fluid and plays an important role in the articular tissues lubrication due to its high molecular weight ${ }^{11}$. Inflammatory and degenerative alteration of the joints reduces the concentration and molecular weight of $\mathrm{HA}^{11,12}$.

$\mathrm{SH}$ injection increases the concentration and molecular weight of HA at the synovial fluid, associated to the relief of pain ${ }^{13}$. By clearing the adherence zones between articular disk and the mandibular fossa, the articular mobility is enlarged allowing a better circulation of the synovial fluid.

It was verified the presence of Prostaglandin E2 and Leukotriene $\mathrm{B} 4$ in the synovial fluid of patients with TMD suggesting that these mediators are among the factors able to generate joint pain ${ }^{14}$. It is also suggested that the analgesic effect of viscosupplementation may occur by blocking receptors and endogenous algic substances in the synovial tissues.

A strictly mechanic mechanism by the interruption of trauma caused by mechanic block of the disk or of both adherence zones was also suggested ${ }^{4}$, what could explain the effects of therapy in medium and long term, because although the injected HA is kept on the joint only for a few days the results last for months ${ }^{15,16}$.
Only two articles reported side effects of the technique, which seem to be brief and self-limiting ${ }^{4,8}$. During the follow-up of the cases reported in this study, no severe side-effect was observed. Most common complaints were mild soreness, edema and open bite at the injection side. However in all cases sideeffects were self-limiting confirming other authors' findings ${ }^{8}$. According to results of this study, viscosupplementation can be considered an efficient alternative for the management of pain and function improvement in patients with RDD, NRDD and OA refractory to conservative treatments.

\section{CONCLUSION}

After the monitoring of clinical cases it is possible to conclude that viscosupplementation with $\mathrm{SH}$ may be an interesting proposal to reduce TMJ pain and improve mouth opening. Controlled clinical trials with significant samples and longer monitoring period are required to evaluate real effectiveness of viscosupplementation technique and to establish an objective protocol.

\section{REFERENCES}

1. Okeson JP, de Leeuw R. Differential diagnosis of temporomandibular disorders and other orofacial pain disorders. Dent Clin North Am. 2011;55(1):105-20.

2. Butler J, Rydel NW, Balazs EA. Hyaluronic acid in synovial fluid. VI. Effect of intra-articular injection of hyaluronic acid on the clinical symptoms of arthritis in track horses. Acta Vet Scand. 1970;11(12):139-55.

3. Kopp S, Wenneberg B. Effects of occlusal treatment and intraarticular injections on temporomandibular joint pain and dysfunction. Acta Odontol Scand. 1981;39(2):87-96.

4. Bertolami CN, Gay T, Clark GT, Rendell J, Shetty V, Liu C, et al. Use of sodium hyaluronate in treating temporomandibular joint disorders: a randomized, double-blind, placebo controlled clinical trial. J Oral Maxillofac Surg. 1993;51(3):232-42.

5. Sato S, Oguri S, Yamaguchi K, Kawamura H, Motegi K. Pumping injection of sodium hyaluronate for patients with non-reducing disc displacement of the temporomandibular joint: two years follow-up. J Craniomaxillofac Surg. 2001;29(2):89-93.

6. Hepguler S, Akkoc YS, Pehlivan M, Ozturk C, Celebi G, Saracoglu A, et al. The efficacy of intra-articular sodium hyaluronate in patients with reducing displaced disc of the temporomandibular joint. J Oral Rehabil. 2002;29(1):80-6.

7. Kopp S, Wenneberg B, Haraldson T, Carlsson GE. The short-term effect of intra-articular injections of sodium hyaluronate and corticosteroid on temporomandibular joint pain and dysfunction. J Oral Maxillofac Surg. 1985;43(6):429-35.

8. Shi ZD, Yang F, He ZX, Shi B, Yang MZ. [Comparative study on effects of sodium hyaluronate and prednisolone injecions on experimental temporomandibular joint osteoarthritis of rabbits]. Zhongguo Xiu Fu Chong Jian Wai Ke Za Zhi. 2002;16(1):510. (Chinese).

9. Kopp S, Akerman S, Nilner M. Short-term effects of intra-articular sodium hyaluronate, glucocorticoid, and saline injections on rheumatoid arthritis of the temporomandibular joint. J Craniomandib Disord. 1991;5(4):231-8.

10. Bonotto D, Custodio L, Cunali P. Viscossuplementation to treat internal temporomandibular joint disorders. Case reports. Rev Dor. 2011;12(3):313-7.

11. Radin El, Paul L. Joint lubrication with artificial lubricants. Arthritis Rheum. 1971;14(1):126-9.

12. Listrat V, Ayral X, Patarnello F, Bonvarlet JP, Simonnet J, Amor B, et al. Arthroscopic evaluation of potential structure modifying activity of hyaluronan (Hyalgan) in osteoarthritis of the knee. Osteoarthritis Cartilage. 1997;5(3):153-60.

13. Swann DA, Radin EL, Nazimiec M, Weisser PA, Curran N, Lewinnek G. The role of hyaluronic acid in joint lubrication. Ann Rheum Dis. 1974;33(4):318-26.

14. Quinn JN, Bazan NG. Identification of protaglandin E2 and leukotriene B4 in the sinovial fluid of painful, dysfunctional temporomandibular joints. J Oral Maxillofac Surg. 1990;48(9): 968-71.

15. Sato S, Ohta M, Ohki H, Kawamura H, Motegi K. Effect of lavage with injection of sodium hyaluronate for patients with nonreducing disk displacement of the temporomandibular joint. Oral Surg Oral Med Oral Pathol Oral Radiol Endod. 1997;84(3):241-4.

16. Alpaslan GH, Alpaslan C. Efficacy of temporomandibular joint arthrocentesis with and without injection of sodium hyaluronate in treatment of internal derangements. J Oral Maxillofac Surg. 2001;59(6):613-9. 